\title{
PARQUES INFANTIS DE 1935 A 1938 E A RELAÇÃO COM A EDUCAÇÃO DESENVOLVIMENTAL E A ATIVIDADE DE ESTUDO
}

\author{
Aline de Novaes Conceição \\ Universidade Estadual Paulista - UNESP, Programa de Pós-Graduação em Educação, Marília, SP. E-mail: \\ alinenovaesc@gmail.com
}

\begin{abstract}
RESUMO
Apresentam-se, resultados de pesquisa realizada com o objetivo de relacionar a educação desenvolvimental e a base da atividade de estudo com os Parques Infantis que funcionaram em São Paulo de 1935 a 1938, período em que Mário de Andrade dirigiu esses parques sendo diretor do Departamento de Cultura. Mediante abordagem histórica centrada em pesquisa documental e bibliográfica, com base nos procedimentos de localizar, reunir e analisar textos que tratassem do funcionamento dos Parques Infantis no estado de São Paulo, como mencionado entre 1935 a 1938; foram consultados sites e bases de dados disponíveis on-line. Além disso, houve a participação e a leitura dos textos propostos na disciplina "Educação Desenvolvimental e Atividade de Estudo". Constatou-se que havia uma relação dos Parques Infantis com uma educação desenvolvimental e havia nesse espaço as bases para a atividade de estudo, considerando que a educação é necessária ao desenvolvimento e apresenta particularidades históricas.

Palavras-chave: Educação. História da Educação. Parques Infantis. Educação desenvolvimental. Vigotski.
\end{abstract}

CHILDREN'S PARKS FROM 1935 TO 1938 AND THE RELATIONSHIP WITH EDUCATION, DEVELOPMENT AND STUDY ACTIVITY

\begin{abstract}
The results of research carried out with the objective of relating developmental education and the base of the study activity with the Children's Parks that operated in São Paulo from 1935 to 1938, period in which Mário de Andrade directed those parks being director of the Department, are presented. of Culture. Through a historical approach focused on documentary and bibliographic research, based on the procedures of locating, gathering and analyzing texts dealing with the operation of Playgrounds in the state of São Paulo, as mentioned between 1935 and 1938; We have consulted sites and databases available online. In addition, there was participation and reading of the texts proposed in the discipline "Developed Education and Study Activity". It was found that there was a relationship between the Playgrounds and a developmentalist education, and there were bases for the study activity in that space, considering that education is necessary for development and has historical characteristics.
\end{abstract}

Keywords: Education. History of Education. Children's Parks. Education developed. Vigotski. 


\section{INTRODUÇÃO}

Apresentam-se neste texto, resultados de uma pesquisa de doutorado realizada com orientação do Dr. Macioniro Celeste Filho sobre os Parques Infantis (PIs) que foram instalados na cidade de São Paulo na década de 1930. Essas instituições ofereciam uma educação não formal e extraescolar; além de assistências médicas, dentárias e alimentares para crianças ${ }^{1}$ pobres filhas de operários (GOBBI, 2012).

A partir dessa constatação, o objetivo geral da pesquisa cujos resultados estão apresentados neste texto, consistiu em de forma inédita relacionar a educação desenvolvimental e a base da atividade de estudo com os Parques Infantis que funcionaram em São Paulo de 1935 a 1938, período em que Mário de Andrade dirigiu esses parques sendo diretor do Departamento de Cultura. O objetivo específico consiste em compreender a atividade de Estudo, a educação desenvolvimental e o funcionamento dos Parques Infantis para as crianças de 3 a 7 anos. Como Farias (1999) defende, estudar os Parques Infantis é contribuir para uma política de Educação Infantil em defesa do direito da criança, uma proposta que possibilita a criança produzir e consumir cultura, sendo criança e sendo protagonista da instituição que frequenta.

\section{METODOLOGIA}

Para o desenvolvimento da pesquisa, mediante abordagem histórica centrada em pesquisa documental e bibliográfica, com base nos procedimentos de localizar, reunir e analisar textos que tratassem do funcionamento dos Parques Infantis (PIs) no estado de São Paulo, como mencionado entre 1935 a 1938; foram consultados sites e bases de dados disponíveis on-line.

Além disso, houve a participação e a leitura dos textos propostos na disciplina da PósGraduação em Educação da UNESP, Câmpus de Marília/SP, intitulada "Educação Desenvolvimental e Atividade de Estudo", ministrada pela professora Dra Stela Miller.

\section{RESULTADOS}

Vigotski, nascido em 1896 e seus colaboradores foram influenciados pelas ideias marxistas, eles demonstraram que há uma relação entre ensino e desenvolvimento, compreendendo que a criança não precisa se desenvolver para aprender, mas o processo educativo e a aprendizagem qualitativa possibilitam o desenvolvimento.

Para cada etapa do desenvolvimento humano, há uma atividade principal, ou seja, a atividade que dela resultará as transformações mais importantes do desenvolvimento. $O$ conceito de atividade é baseado em Leontiev que a considera como orientada a um objeto, gerando um produto que envolve: necessidade; motivo; metas; condições; meios; ações e operações. Com a atividade sempre haverá uma transformação, pois existe uma relação entre o conteúdo assimilado e o desenvolvimento (DAVIDOV, 1999).

Para o bebê a atividade principal é a comunicação emocional direta; para a criança pequena é a manipulação dos objetos; para a criança pré-escolar é o jogo de papéis sociais (jogo simbólico); para a criança escolar é a atividade de estudo; para os adolescentes é a comunicação pessoal; para a criança em idade escolar avançada é a atividade profissional de estudo e para o adulto é o trabalho. Assim a atividade de estudo é a atividade principal de desenvolvimento das crianças das séries iniciais do Ensino Fundamental.

A atividade de estudo possibilita a criança a experimentação e o fazer do professor deve ser o de criar necessidades (DAVIDOV, 1999). Elkonin destacou a estrutura da atividade de estudo, a saber: tarefa de estudo (ações a serem aprendidas); ações de estudo dirigidas a objetivos de estudo; controle do processo de aprendizagem e avaliação dos resultados de aprendizagem.

\footnotetext{
1 Atendia crianças de 3 a 12 anos. Para os menores de 7 anos, os Parques Infantis eram as únicas instituições que elas frequentavam e para os maiores de 7 anos, havia também a frequência à escola. Considerando que para todas as idades atendidas não era obrigatória a frequência aos Pls (FARIA, 1999).
} 
Atividade de estudo deve gerar a superação do pensamento empírico, buscando um conhecimento analítico e reflexivo, para isso, a criança deve sentir necessidade e ter motivo para aprender; transformando o material de estudo com a experimentação. $O$ estudo se faz com a abordagem de solução de problemas tendo o aluno como sujeito da atividade em que o conteúdo é o científico (DAVIDOV, 1988).

Segundo Davidov (1999) com a atividade de estudo é possível transformar o aluno utilizando conteúdo mais complexo, científico e teórico, organizando o aprendizado desses alunos. O mais importante da atividade de estudo não é apreensão do conteúdo teórico, mas a formação de um processo que o permite ser independente para ele próprio realizar a atividade de estudo.

O conteúdo nessa perspectiva, auxilia na formação das crianças e deve ser trabalhado na sua inteireza e não na sua superfície. É importante destacar que cada conteúdo foi constituído conforme necessidades da sociedade, desse modo, em Esparta se ensinava a ler, a escrever, a calcular e preparava fisicamente e militarmente. Em Atenas se ensinava a ler, a escrever, a calcular, a cantar, a declamar, preparava fisicamente e para as classes superiores havia o ensino de filosofia e literatura.

Para comprovar a hipótese de Vigotski sobre a relação de ensino e desenvolvimento, houve um estudo na década de 1930 a 1950. Posteriormente, a morte de Vigotski, foram formados dois coletivos de investigação, o Grupo de Zankov e Elkonin/ Davidov que programaram um ensino, aplicaram e comprovaram que de fato os alunos haviam aprendido. Esses coletivos observaram a escola e constataram que o ensino não transformava os alunos, pois não havia grau de dificuldade (DAVIDOV, 1995).

Assim, planejaram um estudo em ritmo acelerado, com autoconscientização dos estudos e trabalho sistemático para o desenvolvimento de todos. Além disso, com esses coletivos, eles experimentavam, avaliavam, escreviam e compreenderam que a educação poderia ser desenvolvimental (DAVIDOV, 1995).

$\mathrm{Na}$ educação desenvolvimental são considerados: as principais novas formações psicológicas da idade; a atividade principal da faixa de idade que determina o surgimento e desenvolvimento das novas formações correspondentes; o conteúdo e as formas de realização conjunta da atividade; a interconexão com outros tipos de atividade; o sistema de métodos, que permite determinar os níveis de desenvolvimento das novas formações; o caráter da conexão desses níveis com as particularidades da organização da atividade principal e das outras formas de atividades relacionadas (DAVIDOV, 1995).

Em suma, as atividades podem proporcionar o desenvolvimento dos seres humanos e inicialmente, devem ser realizadas coletivamente com base na cooperação, diálogo e discussões, na busca de soluções para tarefas realizadas na Zona de Desenvolvimento Proximal (ZDP). Ao se considerar isso, haverá uma educação que será desenvolvimental, ou seja, proporcionará o desenvolvimento a partir da educação organizada corretamente com a utilização da atividade principal para o desenvolvimento humano da etapa trabalhada (DAVIDOV, 1995).

\section{DISCUSSÃO}

A atividade de estudo pode ser a base para a superação da alienação por ser a busca da essência, essa atividade engloba: análise; reflexão e ação mental, partindo sempre de uma situação-problema do interesse que está dentro da ZDP. A base da atividade de estudo está na Educação Infantil (EI), mas sem escolarização, considerando que a atividade principal das crianças na El são os jogos e as brincadeiras.

Partindo desse pressuposto, como seriam os Parques Infantis para as crianças entre 3 a 12 anos? Haveria relação com a educação desenvolvimental? Considerando que não "[...] se pode falar de educação desenvolvimental em geral, deve-se evidenciar com precisão e confrontar os 
seus diferentes tipos, correlacionar com determinadas condições históricas, com determinada idade.". (DAVIDOV, 1995, p. 12).

Leme (2008) defende que as ideias de Mário de Andrade, que estavam relacionadas com os PIs da década de 1930, podem ser encontradas em Vigotski, pois ele considerava as crianças como sujeitos históricos e produtores de cultura.

Os Parques Infantis existentes no período que passaram a funcionar por intermédio do Departamento de Cultura, sob direção de Mário de Andrade, foram o D. "Pedro II", o da Lapa, o do Ipiranga e o de "Santo Amaro", localizados em São Paulo (NIEMEYER, 2002). Eram instituições que proporcionavam o lazer para os filhos da classe operária, a partir da educação, recreação e assistência, articulando a Educação Física, a cultura e a saúde, reforçando a nacionalidade e inserindo as crianças na arte, no folclore nacional, nos jogos, nas brincadeiras (inclusive as tradicionais). Possibilitando às crianças o direito à infância não tendo contato com a préalfabetização, mas brincando, realizando atividades artísticas e não trabalhando.

Nos PIs, havia aparelhos educativos para recreação e ginástica como: gangorra, carrossel e deslizadores, havia também o tanque de vadear (tanque de areia), piscina, pátio para as refeições ${ }^{2}$, bibliotecas e uma ou duas salas para atividades didáticas (VIEIRA, 2004). Os PIs da década de 1930, estavam relacionados com a política cidadã de desenvolvimento urbano dessa década, que privilegiava "[...] interesses lúdicos e culturais fortemente presentes em uma planta arquitetônica de poucas salas (nenhuma de aula), muitas árvores, areia e brinquedos. " (NIEMEYER, 2001, p. 89).

Dentre os profissionais que trabalhavam nos Parques Infantis havia: administradores, instrutores, educadores físicos, dentistas e médicos ${ }^{3}$. A partir de 1936, houve a presença da educadora sanitária que também realizava visitas domiciliares às crianças parqueanas, ou seja, nos PIs ocorria a integração entre cultura, educação e saúde.

Os instrutores eram indicados pelo Instituto de Educação de São Paulo e tinham como formação o curso realizado na Escola Normal e outro curso que poderia ser: de educadores sanitários realizado no Instituto de Higiene de São Paulo; de Educação Física Infantil realizado no Departamento de Educação Física do Estado ou especialização pré-primária realizada no Instituto de Educação da Universidade de São Paulo (FARIAS, 1999).

Destaca-se que para trabalhar na escola primária do período, somente era exigido o Curso Normal e nos PIs precisava ter um curso complementar ao normal, o que demonstra a preocupação com a qualidade educativa dos Parques Infantis. Assim, nos Pls o recrear "[...] era uma função educativa que requeria pessoas qualificadas para atender aos filhos dos operários. " (SANTOS, 2005, p. 73).

Os Pls eram como praças públicas, com divertimento, educação e produções de culturas infantis, com profissionais preparados para ensinar as crianças a brincarem (FARIA, 1999).

Segundo Miranda (1941), os PIs estavam em um espaço que educava e prestava assistência e para Mário de Andrade essa instituição era educativa e ligada à cultura e a saúde. Todavia, os parques não eram assistencialistas, pois cuidavam da educação de forma integral, considerando o ser humano como um todo, em que o crescimento físico e intelectual faz parte do mesmo processo do ser histórico e social, ou seja, essas instituições possibilitavam a junção entre cuidar e educar, buscava com os Parques Infantis que a criança pobre sobrevivesse para que fosse construído um Brasil melhor.

Mário de Andrade possibilitou o enriquecimento de uma educação que considerava a criança como criança e produtora de conhecimento e não somente como aluno ou como um

\footnotetext{
2 Devido à desnutrição de muitos parqueanos, eram servidas merendas diárias com frutas, doces, pão, queijo e leite (VIEIRA, 2004).

${ }^{3}$ Esse profissional se justifica pelo fato de $60 \%$ das crianças parqueanas apresentarem sintomas de desnutrição sendo que a maioria apresentava duas ou três doenças contagiosas e as mais comuns eram: gripe, coqueluche, amigdalite, escabiose, varicela, sarampo, conjuntivite aguda, difteria, sífilis, tuberculose e escarlatina (KUHLMANN; FERNANDES, 2014).
} 
adulto do futuro, uma educação que não descriminava a origem social e reconhecesse "[...] a existência de vários tipos de conhecimento (científico, artístico, acadêmico, não-acadêmico etc.) " (FARIA, 1999, p. 195).

Mário de Andrade buscava integrar mente, corpo, cognição, afeto e emoção e defendia que não se deveria tratar a pobreza de maneira pobre, pois “[...] ao pensar que não está educando, corre o risco de educá-la apenas para a ordem e disciplina, portanto, apenas reproduzindo a força de trabalho." (FARIA, 1999, p. 206).

Ao analisar as manifestações artísticas das crianças nos Parques Infantis de São Paulo em 1937 e 1938, é possível considerar que havia dança, pintura, desenho, jardinagem; os meninos realizavam marcenaria e as meninas modelagem e trabalhos manuais. Nesses parques havia também concurso de desenho paras as crianças e os desenhos eram enviados com os nomes e idades das crianças para o Departamento de Cultura e os três primeiros lugares ganhavam prêmios em dinheiro e compravam o que queriam juntamente com as instrutoras (GOBBI, 2004).

Faria (1999) defende que com os PIs era possibilitado o direito ao brincar que não era garantido para as crianças pobres, que muitas vezes tinham que trabalhar. Em 1974, com o documento de criação das Escolas Municipais de Educação Infantil (EMEIs), há a eliminação dos objetivos do PI relacionado ao lúdico, aos jogos tradicionais e aos objetivos artísticos, pois as "[...] EMEls tem a tendência crescente em adotar o modelo escolar. O projeto inicial do PI apresentava a postura de criticar a escola da época e propor-se a complementá-la.", integrando o cuidar e o educar (FARIA, 1999, p. 157).

Segundo Farias (1999) os Parques Infantis de São Paulo funcionaram até 1975, quando foram transformados em Escolas Municipais de Educação Infantil e passaram a apenas receber crianças de 3 a 7 anos.

\section{CONSIDERAÇÕES FINAIS}

Os Parques Infantis que funcionaram em São Paulo de 1935 a 1938, período em que Mário de Andrade dirigiu esses parques a partir da direção do Departamento de Cultura, foram instituições que estavam ao encontro com uma educação desenvolvimental. Por considerarem a atividade principal do desenvolvimento da criança pré-escolar e propiciar que elas brincassem e fizessem atividades recreativas a partir do cuidado e educação desenvolvidos por pessoas formadas que tinham complemento ao Curso Normal que formava professores no período.

Assim, a recreação do parque exigia pessoas qualificadas que pudessem planejar atividades desenvolvimentais que abrangessem a educação integral da criança, possibilitando que elas dançassem, desenhassem, tivessem atividades físicas, fizessem trabalhos manuais, jardinagem, modelagem entre outras atividades que consideram as crianças como seres integrais.

Partindo do pressuposto de que a criança deveria brincar e não deveria ser preparada para apenas escrever e ler, função que era do Ensino Fundamental, ou como denominado no período histórico em questão, Ensino Primário. Assim, os Pls cuidavam e educavam com poucas salas, muitas árvores e muitos brinquedos.

Apesar de não ter sido possível constatar se havia a problematização com as crianças nos PIs, é possível compreender que havia uma relação dos PIs com uma educação desenvolvimental e havia nesse espaço as bases para a atividade de estudo, considerando que a educação é necessária ao desenvolvimento e tem particularidades históricas.

Com os PIs, havia a possibilidade de que as crianças se humanizassem a partir de atividades e conhecimentos humanos mediados pelos conteúdos históricos, sociais e culturais do seu entorno, atividades que possibilitavam o desenvolvimento. Considerando que não é toda educação que gera desenvolvimento, mas a condução correta por parte do professor possibilita que a criança se desenvolva com a educação. 


\section{REFERÊNCIAS}

DAVYDOV, V.V. Problems of Developmental Teaching. The Experience of Theoretical and Experimental Psycholgogical Research - Excerpts. In: Revista Soviet Education, [S.I.], v. 30, n.8, p. 15-97, 3-83, 3-77, ago. 1988.

. Acerca do conceito de educação desenvolvimental. Pedagogia, [S.I], n.1, p.1-15., 1995.

. O que é atividade de estudo, Revista Escola inicial [S.I.], n.7, p.1-7., 1999.

FARIA, Ana Lúcia Goulart de. Educação Pré-Escolar e Cultura. Campinas: Cortez, 1999.

GOBBI, Márcia Aparecida. Desenhos de outrora: os desenhos de crianças pequenas do acervo Mário de Andrade. 2004, 203f. Tese (Doutorado em Educação) - Faculdade de Educação, Universidade Estadual de Campinas, Campinas, 2004.

a. Conhecimento histórico e crianças pequenas: parques infantis e Escola Municipal de Educação Infantil. Educação em Revista, Belo Horizonte, v.28, n. 2, p.203-224, jun. 2012. https://doi.org/10.1590/S0102-46982012000200010

KUHLMANN JÚNIOR, Moysés; FERNANDES, Fabiana Silva. Educação, cultura e infância no Parque Infantil paulistano (1947-1957). Rev. Diálogo Educ., Curitiba, v.14, n.43, p.693-716, set./dez. 2014.

LEME, Fernanda de Lucca. Memórias de um Parque Infantil em Campinas: vestígios do pensamento de Mário de Andrade. 2008, 92f. Dissertação (Mestrado em Educação)- Faculdade de Educação da Universidade Estadual de Campinas, Campinas, 2008.

MIRANDA, Nicanor. Origem e propagação dos parques infantis e parques de jogos. São Paulo: Departamento de Cultura, 1941.

NIEMEYER, Carlos Augusto da costa. Urbanização e lazer a contribuição lúdica-pedagógica dos parques infantis de São Paulo nas primeiras décadas do século 20.

Pós. Revista do Programa de Pós Graduação em Arquitetura e Urbanismo da FAU/USP, São Paulo, v.10, p. 76-91, 2001.

. Parques infantis de São Paulo: lazer como expressão de cidadania. São Paulo: Annablume: Fapesp, 2002.

SANTOS, Maria Walburga dos. Educadoras dos parques infantis em São Paulo: aspectos de sua formação e prática entre os anos de 1935 a 1955. 2005. 299f. Dissertação (Mestrado em História e Historiografia da Educação)- Faculdade de Educação, Universidade de São Paulo, 2005.

VIEIRA, Sandra Aparecida Basseto. Os parques infantis da cidade de São Paulo (1935-1938): análise do modelo didático-pedagógico. Revista de Iniciação Científica da FFC, v.4, n.1, p. 117-133, 2004. 